with the courage and spirit to see it through, and it is very doubtful if such reward falls to the lot of the reasonably successful civil engineer.

Civil engineering is, if we may use the mathematical analogy, the second differential of the profession, the aim of which is the acceleration of normal progress; and in the earlier years of this century when everything was alive with expansion, there was no doubt in the truth of the statement that a civil engineer could walk the length of Victoria Street, London, and find himself with a dozen excellent assignments to choose from. Those good days are, however, past, and we live in more sober times, added to which the 'dynamic' side of engineering has made immense strides both in the width of its products and in their application to industry. What could offer higher adventure than the development of the jet engine, or radar; or the smooth and effective running of a complicated human machine such as a works of some thousands of hands, with all the problems of production control and the enjoyment of the command of men : and with all this, more security of tenure and, we think, very appreciably greater financial reward? Higher executives in engineering firms or industry can look to salaries of $£ 1,000-£ 1,500$ or more from about the age of thirty-five onwards, a level which we doubt can be expected by a resident civil engineer of comparable age, technical training and experience.

This, then, is the competition which civil engineering has to face. The insecurity, save for the fortunate few who may perhaps become partners in a firm of repute, seems inevitable. Manufacturing industry is a continuous process, slow or fast maybe, but in steady motion, whereas big public works are dependent for their life on a wide variety of circumstances and are the first to be hit by any period of depression. May it be hoped, therefore, that to attract to this branch of the profession the best young men, as it well deserves, the rewards will be very real. Consultants' expenses are high, but surely on a contract totalling some hundreds of thousands of pounds a rise in the price of that essential raw material, namely, the resident engineer's skill and devotion, would scarcely make an appreciable difference.

Certain branches of civil engineering are of the 'service' type, with a planned career, but we are not sure even here whether the terms offered are fairly aligned with those in other careers of a similar nature. It might not be unwarranted to draw an analogy between such careers and the financial world, where the yield of government securities largely regulates the gilt-edged market. This analogy is pointed by the terms recently offered by the Government Scientific Service, designed to attract the best material of Britain to a career which cannot offer more than a fair reward compatible with security and pension. It would be extremely interesting to compare these with the prospects ahead of a young engineer in, say, one of the railways.

Civil engineering suffers from a further disadvantage at the other end of the scale, namely, the conditions of entry. Criticism on this count is now, to some extent, disarmed by the reference on page 12 of the brochure to recent arrangements made between the Institution of Civil Engineers and both the Institution of Municipal and County Engineers and the Federation of Civil Engineering Contractors, for the proper training of young engineers entering the profession through these two latter channels. We understand, although it is not mentioned, that the scheme envisages a salary of the order of $£ 250-£ 300$ a year for a two-year indenture. This is a most excellent move on which the Institution of Civil Engineering is to be congratulated, the level being approximately the same as that now offered by the big 'training' firms in the electrical and mechanical world. Contracting and municipal engineering are, however, only branches of civil engineering so to speak, and it is a matter of some regret that the lead. in improved conditions for training has not been given by the 'core' of the profession, namely, the consultants. The chapter on consulting engineering includes only a somewhat vague and unsatisfactory reference to the proper method of entry, together with an ominous, and surely unnecessary, warning of the perils of aiming at too high a salary in early years. The young engineer of to-day is a young man with a very realistic view of life and a readiness to learn his craft thoroughly-provided it does not entail his being a burden on his heavily taxed parents.

\section{BOMBYLIIDAE OR BEE FLIES OF EGYPT}

$T$ HE Bombyliidæ or bee flies are very well represented in a warm, sunny country like Egypt. They are an ofedefionally interesting group of Diptera to the extorologist, not only on account of the remarnab -range of form displayed by the adult fNs b lat also owing to the curious parasitic habits of Nhe ir larvæ. Prof. Efflatoun Bey has recently made a very detailed study of the Egyptian species*, and the results of his labours form Part VI of his well. known "Monograph of Egyptian Diptera".

The Bombyliidæ are poorly represented in cold or cool countries, but they rapidly increase in number of species as we pass southwards. Thus, the author mentions that while there are only nine British species and fourteen Danish forms, some sixty kinds are recorded by Schiner from Austria and 115 from Spain. In 1924, 594 species were known from the Ethiopian region, and that number is only a small proportion of those that probably remain still to be discovered. In 1919, fewer than fifty species of bee flies were known from Egypt, but to-day that number is more than quadrupled. For reasons of economy and convenience, the results of Prof. Efflatoun's study are to appear in two parts. The present, on Section I, deals with the Bombyliidæ Homœophthalmæ or those in which the compound eyes are simple, that is, not indented on the hind margin. Section II, dealing with the Bombyliidæ Tomophthalmæ, or those in which the eyes are evidently indented, will, it is hoped, be published in the near future. A series of beautiful coloured plates have characterized the previous parts of this monograph, and their absence from the present section immediately attracts notice. Prof. Efflatoun mentions that they cannot be published at present owing to difficulties arising out of the War, but it is expected that they will be issued later. On the other hand, the work is very well illustrated by some 38 black-and-white plates comprising more than 550 well-drawn figures of structural details pertaining to the different species.

At the present time nothing is known concerning the early stages of these flies in Egypt, and here a wide field of inquiry awaits a competent investigator.

* A Monograph of Egyptian Diptera. Part VI. Family Bombyliidx. Section I. By Prof. H. C. Efflatoun Bey. Bull. Sor. Fouad $1^{\text {or }}$ d’Entomo- $^{\prime}$ '
logie, pp. $482+38$ pl., 1945 . 
Elsewhere it is known that a number of species attack one or other kind of migratory locust in the egg stage. Other Bombyliidæ parasitize the caterpillars of moths or the larvæ of solitary bees and fossorial wasps. Fabre, for example, gave an interest. ing account of a species that lives at the expense of the mason bee. One species has been bred from the puparia of tsetse flies (Glossina) and others are hyperparasites.

In Prof. Efflatoun's opinion the systematic arrangement of the Bombyliidæ still awaits a competent monographer, notwithstanding the labours of such authorities as Becker and Bezzi. The limits of some of the subfamilies are by no means well defined and the allocation of various genera is open to doubt. Possibly, as Bezzi originally suggested, a closer knowledge of the bionomics and ethnology of the family will lead to a better taxonomy. The Bombyliid fauna of Egypt, as with many othor families, undoubtedly forms, according to Prof. Efflatoun, a connecting link with the Palæarctic and Ethiopian zoogeographical regions.

A. D. Imms

\section{RECONSTRUCTION IN THE ASSAM HILLS}

$\mathrm{T}$ HE process of reconstruction must vary in different locellifes, but in most cases the anthro-

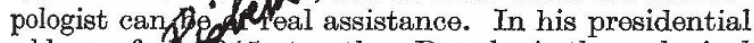
address for $\$ 945$ to the Royal Anthropological Instifut of Great Britain and Ireland, Prof. J. H. Hift discussed some problems of reconstruction as hiey will appear in the Assam Hills. Any hill-tribe tends to lead a more or less segregated life, and until this century the Nagas had had only sporadic communication with the outside world. The First World War was responsible for a certain amount of contact, but it was not until the recent campaign in their country that any large-scale opening-up occurred. Now there are good roads, and communication by air is also established.

Communications, with the labour necessary to maintain them, will mean a steady flow of money, in the form of wages, into the country; and with the further opening-up of Burma and Assam, the Nagas will inevitably have to relinquish their position of isolation. Indeed, one curious result of the Japanese invasion was that it gave the Nagas a feoling of partnership with the other peoples who were fighting the common foe, and proved them most loyal and helpful to the Allies.

In return for this, it behoves us to see that the changes that have been wrought so suddenly should be beneficial and not detrimental to this fine race. They have an intense love of independence. They are asking for education; but it must be the right sort and benefit the whole community, rather than create a class of minor clerks who will try to exploit the less bookish members.

Another problem concerns the administration of the district : to what degree the Nagas are capable of indirect rule, and how far collective responsibility may be a workable proposition. Then, too, there is the language question, for example, whether the higher education should be given in English or Assamese; and if the latter, which of the several dialects should be used and reduced to writing. Cultivation of the hill country is another important question : removal of the forests reduces the rainfall necessary for the irrigation of the terraces which have replaced the tree-covered slopes, thus setting up a vicious circle from which there seems no escape since rice is a staple food.

These, then, are some of the problems of this area, a comparatively small one, and similar problems on a larger scale await solution in practically all south-east Asia, Indonesia and Oceania. The need for applied anthropology is unquestionable. Changes there are, and must increasingly be, and it is the duty of those responsible for administration to see that the welfare of indigenous peoples is the first consideration.

K. R.

\section{LAMARCK BICENTENARY CELEBRATIONS}

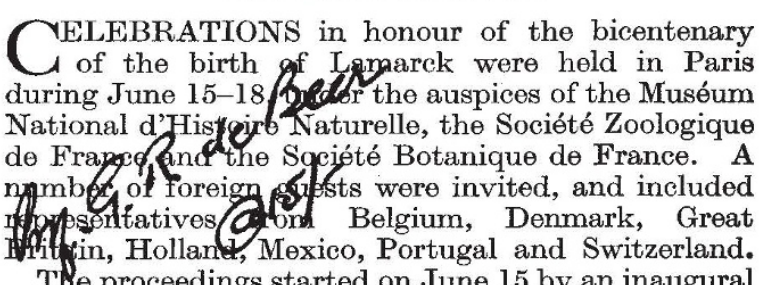
The proceedings started on June 15 by an inaugural session in the great amphitheatre of the Museum under the chairmanship of the Ministre de l'Education Nationale. The chief events in the life of Lamarck were traced by M. A. Urbain, director of the Museum; M. H. Humbert spoke of Lamarck's contributions to botany, and M. R. Jeannel of his services to zoology; Prof. M. Caullery reviewed the significance of Lamarck's work from the point of evolution, and assessed the position which it oecupies to-day.

The morning of June 16 was devoted to a demonstration of exhibits relating to the life of Lamarck; a charming and interesting feature of the occasion was the presence of representatives of Lamarck's family, in the persons of his great-great-grandsons. A wreath was laid at the foot of Lamarck's statue, and the delegates then attended a banquet presided over by the Directeur des Rélations Culturelles of the Ministère des Affaires Etrangères. In the afternoon the delegates were taken over the Musée de l'Homme by its founder and director, M. Rivet.

On June 17, the delegates were taken to the Zoological Park at Vincennes, where they had the opportunity of seeing many interesting animals and of learning of the difficulties encountered-and largely surmounted-in obtaining food for them. After enjoying the wonderful view from the top of the Grand Rocher, the delegates were entertained to luncheon by their hosts under the chairmanship of the Directeur de L'Enseignement Supérieur of the Ministère de L'Education Nationale. After returning to Paris the delegates attended a reception at the Laboratoire d'Evolution des Etre Organisés.

From this point, the programme was divided, and the delegates attended meetings of the Société Zoologique and of the Société Botanique, respectively, including demonstrations and communications.

The proceedings were marked by the greatest cordiality, and the trouble taken by the organisers in the face of considerable difficulties as regards food and accommodation was deeply appreciated by the visitors, who were very grateful for the opportunity to renew old friendships and make new ones while paying tribute to the name of Lamarck. 